\title{
Hepatocellular Carcinoma
} with Foamy Histiocyte-Like Appearance: A Deceptively Clear Cell Carcinoma Appearing Variant

\author{
Takuji Noro $^{\mathrm{a}}$ Naoto Gotohda ${ }^{\mathrm{a}}$ Motohiro Kojima ${ }^{\mathrm{b}}$ \\ Masaru Konishi ${ }^{a}$ Toshio Nakaghori ${ }^{a}$ Shinichiro Takahashi ${ }^{a}$ \\ Takayuki Hasebe ${ }^{c}$ Taira Kinoshita ${ }^{a}$ \\ aDepartment of Hepatobiliary Pancreatic Surgery, bPathology Division, \\ Research Center for Innovative Oncology, and 'Surgical Pathology Section, \\ Clinical Laboratory Division, National Cancer Center Hospital East, Kashiwa, Japan
}

\section{Key Words}

Hepatocellular carcinoma $\cdot$ Variant $\cdot$ Clear cell carcinoma

\begin{abstract}
Hepatocellular carcinoma (HCC) shows many pathological features, and it varies architecturally and cytologically. There have been many reports and discussions of the morphological features of HCC. A 63-year-old man was found to have a solitary tumor in liver segment 7 that was diagnosed as HCC. A partial resection of liver segment 7 was performed. Microscopically, the tumor lesion showed a moderately differentiated HCC. There was also a lesion with foamy histiocyte-like cells corresponding to the white lesion in the face of the cut tumor. Immunohistochemical staining showed that they were negative for CD68, S-100, vimentin, and HMB-45. The cytoplasm itself was negative on periodic acid Schiff (PAS) and Sudan staining. Without immunohistological analysis, it is difficult to distinguish this HCC variant from clear cell carcinoma or metastases of renal cell carcinoma. It is important to recognize this type as a specific cytological variant of $\mathrm{HCC}$ that requires confirmation by immunohistochemistry. This report describes the case of a patient with a morphologically distinctive pattern of HCC with prominent cell cytoplasm that had a foamy histiocyte-like appearance. To the best of our knowledge, this is the first report of this HCC variant.
\end{abstract}




\section{Introduction}

Hepatocellular carcinoma (HCC) shows many pathological features, and it varies architecturally and cytologically. The differential architectural pattern and cytological variations frequently occur in combination [1]. A variety of cellular products, mimicking normal and pathologic liver cell function, can sometimes be seen by light microscopy or identified by various histochemical and immunohistochemical techniques. For example, large amounts of cytoplasmic fat or glycogen can cause the cytoplasm to appear white in routine sections, producing the so-called clear cell carcinoma of the liver [2].

There have been many reports and discussions of the morphological features of HCC, but there have been no reports of a variant of HCC that is characterized by abundant foamy cells with microvesicular cytoplasm. A case is presented of a patient with a morphologically distinctive pattern of HCC with dominant cytoplasm giving the cells a foamy histiocyte-like appearance, and the histochemical and immunohistochemical characteristics of this tumor are documented.

\section{Case Report}

A 63-year-old man had been followed up for chronic hepatitis C since 1998 at another medical facility. In September 2006, a tumor was found in liver segment 7 that was diagnosed as HCC. The patient was referred and admitted to our hospital. His past medical history included only hypertension. There was no family history of hepatic disease. On admission, physical examination revealed no abnormalities. Laboratory findings included: WBC 6,000/ $\mu \mathrm{l}, \mathrm{RBC} 488 \times 10^{4} / \mu \mathrm{l}, \mathrm{Hb} 15.5 \mathrm{~g} / \mathrm{dl}, \mathrm{Ht} 45.9 \%$,

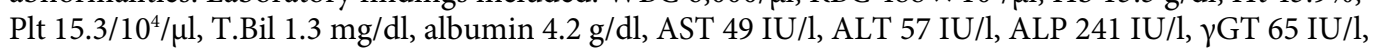
PT 77\%, and ICG R15 20.4\%. AFP was $17.9 \mathrm{ng} / \mathrm{ml}$, and PIVKA-II was $202 \mathrm{mAU} / \mathrm{ml}$. Hepatitis C virus antibody was positive.

Abdominal ultrasonography and computed tomography examinations showed a solitary mass $45 \mathrm{~mm}$ in diameter in liver segment 7 . The mass had a regular circumference, a very clear boundary, and a fibrous capsule. It showed heterogeneous enhancement in the early phase and comparatively low density in the late phase. An area with fat deposition coexisted with a hypervascular area (fig. 1A). T1-weighted magnetic resonance imaging (MRI) showed irregular and slightly high intensity with arterial enhancement, and nonuniform high-intensity areas with prominent fatty change. T2-weighted MRI showed a high-intensity lesion in the same area. On abdominal dynamic MRI, the tumor showed prominent fat deposition inside, and it was heterogeneous, with high intensity on T1-weighted images in the arterial phase (fig. 1B). Ultrasonography demonstrated that there was no vessel invasion (fig. 1C). These examinations suggested that the preoperative diagnosis was a relatively well-differentiated, nodular type of HCC with fatty change and a clinical stage I according to the TNM classification.

A partial resection of liver segment 7 was performed. The operative findings showed that this was HCC without metastases. The patient's postoperative course was satisfactory, and he was discharged on postoperative day 9 without complications. Currently, about 2.5 years after surgical resection, he has had no recurrence.

Macroscopically, the tumor presented as a single mass measuring $4.5 \times 4.1 \times 3.5 \mathrm{~cm}$. The liver margin in the specimen was negative for cancer. The cut surface of the tumor was a yellow-white color, with a white part in the central area that was expansive and protruded. This showed nodular type HCC (fig. 2). Microscopically, the noncancerous lesion showed infiltration of inflammatory cells and rhexis images of the limiting plate at the periportal region; this was diagnosed as active chronic hepatitis. The tumor lesion showed a moderately differentiated HCC that consisted mainly of a thick trabecular pattern, with some thin parts and other thick parts. There was also the lesion with cells with clear cytoplasm corresponding to the white lesion in the face of the cut tumor (fig. 3). The white lesion contained rich fatty tissue. Despite the fact that it was a moderately differentiated adenocarcinoma, with a diameter of $45 \mathrm{~mm}$, it had a fat-rich lesion [3]. Immunohistochemical staining was performed. The lesion was mainly composed of foamy histiocyte-like cells, which were negative for CD68, S-100, vimentin, and HMB-45. Cytologically, the lesion contained medium-small fat vacuoles that were negative for PAS-ALB. The cytoplasm itself was negative on PAS and Sudan staining (fig. 3). The other immunohistochemistry and histological findings are shown in table 1. 


\begin{tabular}{r|l|l|l} 
Case Reports in & $\begin{array}{l}\text { Case Rep Gastroenterol 2010;4:286-292 } \\
\text { Dol: 10.1159/000319545 }\end{array}$ & Published online: August 3, 2010 & $\begin{array}{l}\text { O 2010 S. Karger AG, Basel } \\
\text { ISSN 1662-0631 } \\
\text { www.karger.com/crg }\end{array}$ \\
& & & \\
\hline
\end{tabular}

\section{Discussion}

It was interesting that these tumor cells showed a unique, clear, foamy appearance. Adsay et al. [4] reported foamy pancreatic adenocarcinoma that lacked PAS positivity [5]. There have been no reports of HCC with morphological characteristics that appeared like foamy histiocytes phagocytosing fat. Histiocytes are well known as cells that have a foamy appearance [6,7]; they are positive on immunohistochemistry for CD68 [8]. However, in the present case, the foamy histiocyte-like cells were negative for CD68, and they had a clear cytoplasm and a foamy appearance that, at quick glance, appeared to be due to granules. There is a variety of HCC that has clear cytoplasm, and it is known as clear cell HCC.

HCC cells resemble normal liver cells to a variable extent, depending on the degree of differentiation. They may also contain a variety of cellular products. A large amount of cytoplasmic glycogen and/or fat can cause the cytoplasm to appear white in routine sections, producing a clear cell appearance [2]. Recently, clear cell carcinoma was reported to occur with a frequency varying from 0.9 to $8.8 \%$ in a large series of HCCs from many different countries [5, 9-13].

Microscopically, clear cell HCC shows moderate-to-marked cytoplasmic accumulation of glycogen and/or fat droplets that dissolve during processing, leaving behind a clear area [14]. Without immunohistochemistry, it may be difficult to distinguish between morphological differentiation of clear cell HCC and other clear cell carcinomas, such as metastases from renal clear cell carcinoma $[11,13,14]$. In this case, hepatocyte paraffin 1 (Hep-Par 1), which is a monoclonal antibody that reacts with hepatocytes and can be used for differential diagnosis of hepatic tumors [15], was used to confirm that the foamy histiocyte-like lesion was derived from hepatocytes, because it was positive for Hep-Par 1. The cytoplasm did not contain glycogen or mucin, because PAS and Sudan stains were negative. The other immunohistochemical and histopathological findings suggested that this tumor was a HCC; nevertheless, it was not clear cell HCC.

Adsay et al. [4] reported a morphologically distinctive foamy pattern of pancreatic ductal adenocarcinoma with prominent microvesicular cytoplasm, giving the cells a foamy appearance. The cells were negative for PAS. They concluded that this was prone to being misdiagnosed as a benign tumor. It is difficult to identify the role that the foamy glands have. Furthermore, these lesions may be confused with hepatic metastases of renal cell carcinoma or clear cell HCC because of the small amount of tissue obtained when biopsies of tumors are performed. This case was a cytological variant of HCC that had foamy histiocyte-like features. Without immunohistological analysis, it is difficult to distinguish HCC with foamy histiocyte-like features from clear cell carcinoma or metastases of renal cell carcinoma. It is important to recognize this type as a specific cytological variant of HCC that requires confirmation by immunohistochemistry. Nevertheless, it was unclear whether the tumor cells differed from those of normal HCC.

This report describes the case of a patient with a morphologically distinctive pattern of HCC with prominent cell cytoplasm that had a foamy histiocyte-like appearance. To the best of our knowledge, this is the first report of this HCC variant. Further follow-up and accumulation of cases are needed. 
Table 1. Immunohistochemical findings in foamy histiocyte-like cells

\begin{tabular}{llll}
\hline Hep-1 & + & -1 AE1 & - \\
S-100 & - & AFP & - \\
Vimentin & - & CD10 & - \\
PAS & - & CK5.6 & - \\
Sudan & - & CK7 & - \\
CD68 & - & CK20 & - \\
CAM 5.2 & + & EMA & - \\
HMB-45 & - & Lu243 & - \\
MIB-1 & - & a1-AT & - \\
\hline
\end{tabular}

Fig. 1. A-1 In the early phase, the lesion shows heterogeneous enhancement. A-2 In the portal phase, the lesion shows an isodensity area. A-3 In the late phase, the lesion shows a comparatively low density. B Abdominal dynamic MRI. B-1 Early phase. B-2 Portal phase. B-3 Late phase. C Ultrasonography demonstrates no vessel invasion. The boundary of the tumor is very clear, and there is a low-echoic lesion in the high-echoic mass.
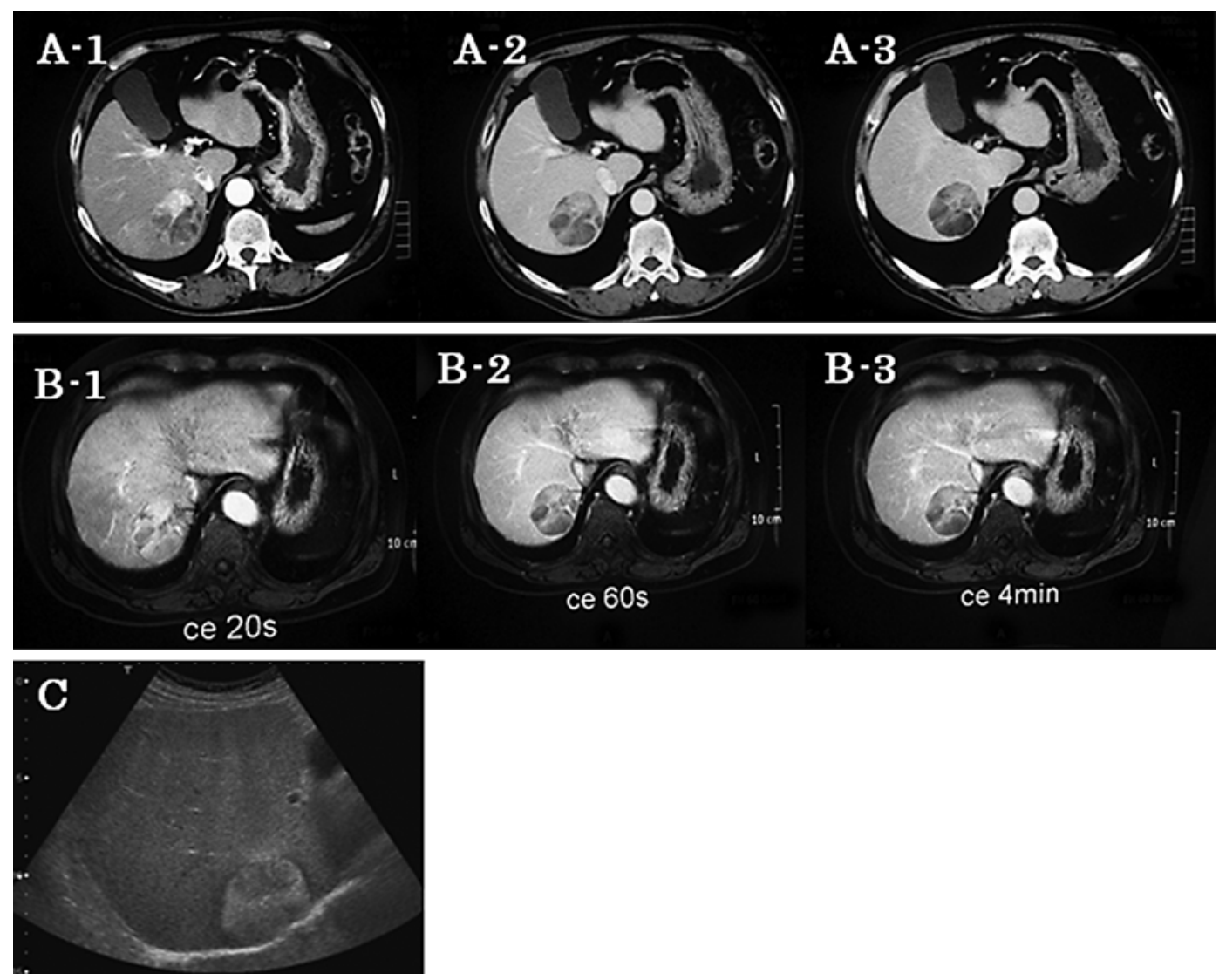


\begin{tabular}{r|l|l|l} 
Case Reports $h$ & Case Rep Gastroenterol 2010;4:286-292 & Published online: August 3, 2010 & $\begin{array}{l}\text { @ 2010 S. Karger AG, Basel } \\
\text { ISSN 1662-0631 } \\
\text { wwww.karger.com/crg }\end{array}$
\end{tabular}

Fig. 2. A white area (arrowheads) is seen in the central part with a yellowish-white-like lesion (arrows); this was nodular type HCC and corresponds with the high-density area on the early-phase computed tomography.

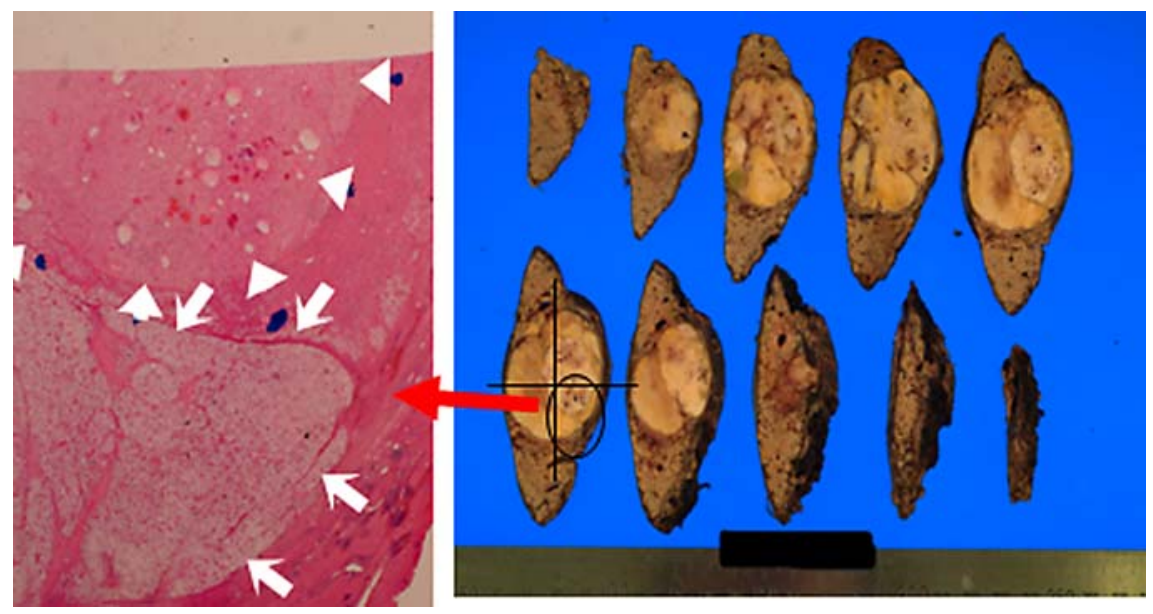




\begin{tabular}{r|l|l|l}
$\begin{aligned} \text { Case Reports in } \\
\text { Gastroenterdagy }\end{aligned}$ & $\begin{array}{l}\text { Case Rep Gastroenterol 2010;4:286-292 } \\
\text { D0I: 10.1159/000319545 }\end{array}$ & Published online: August 3, 2010 & $\begin{array}{l}\text { O 2010 S. Karger AG, Basel } \\
\text { ISSN 1662-0631 } \\
\text { www.karger.com/crg }\end{array}$ \\
\hline
\end{tabular}

Fig. 3. A 40×, B 100×, C 200×, D 200×. Histologically, the white lesion in the tumor shows mainly moderately differentiated HCC, with a slightly thick trabecular pattern. It was confirmed that this consisted of clear, foamy histiocyte-like cells. On the other hand, the yellowish-white-like lesion shows many fat drops within it. These two parts are clearly incompatible. E-L On histochemistry and immunohistochemistry, the tumor is positive for Hep-Par 1, but all other stains are negative, including PAS, Sudan, CD68, S-100, MIB-1, and vimentin.

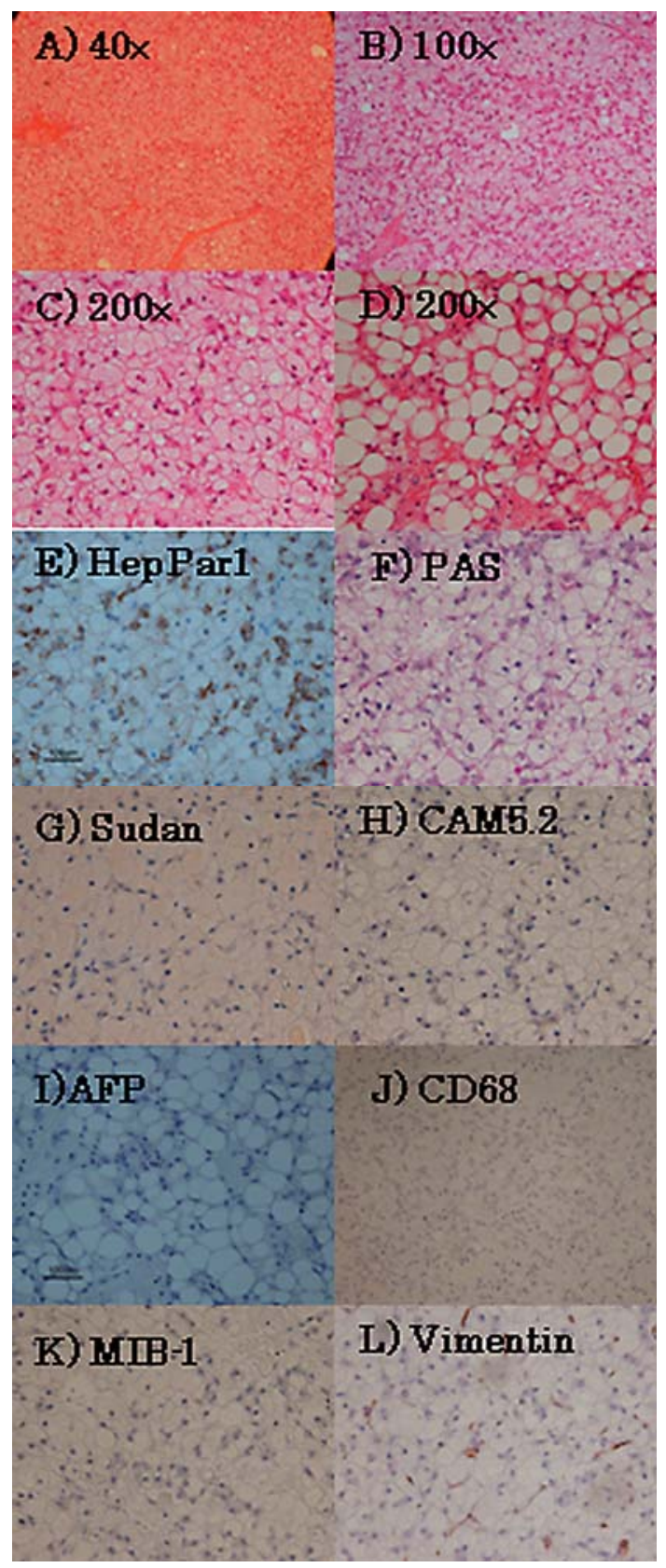




\section{References}

1 Hamilton SR, Aaltonen LA (eds): Tumours of the Digestive System. Lyon, IARC Press, 2000, p 164.

2 Ishak KG, Goodman ZD, Stocker JT (eds): Tumors of the Liver and Intrahepatic Bile Ducts. Washington, American Registry of Pathology Armed Forces Institute of Pathology, 2001, p 207.

- 3 Kojiro M: Histopathology of liver cancers. Best Pract Res Clin Gastroenterol 2005;19:39-62.

-4 Adsay V, Logani S, Sarkar F, Crissman J, Vaitkevicius V: Foamy gland pattern of pancreatic ductal adenocarcinoma: a deceptively benign-appearing variant. Am J Surg Pathol 2000;24:493-504.

5 Adamek HE, Spiethoff A, Kaufmann V, Jakobs R, Riemann JF: Primary clear cell carcinoma of noncirrhotic liver: immunohistochemical discrimination of hepatocellular and cholangiocellular origin. Dig Dis Sci 1998;43:33-38.

-6 Bejarano PA, Aranda-Michel J, Fenoglio-Preiser C: Histochemical and immunohistochemical characterization of foamy histiocytes (muciphages and xanthelasma) of the rectum. Am J Surg Pathol 2000;24:1009-1015.

7 Cozzutto C, Carbone A: The xanthogranulomatous process.

Xanthogranulomatous inflammation. Pathol Res Pract 1988;183:395-402.

8 Cline MJ: Histiocytes and histiocytosis. Blood 1994;84:2840-2853.

-9 Buchanan TF Jr, Huvos AG: Clear-cell carcinoma of the liver. A clinicopathologic study of 13 patients. Am J Clin Pathol 1974;61:529-539.

10 Emile JF, Lemoine A, Azoulay D, Debuire B, Bismuth H, Reynes M: Histological, genomic and clinical heterogeneity of clear cell hepatocellular carcinoma. Histopathology 2001;38:225-231.

-11 Kashala LO, Conne B, Kalengayi MM, Kapanci Y, Frei PC, Lambert PH: Histopathologic features of hepatocellular carcinoma in Zaire. Cancer 1990;65:130-134.

-12 Lai CL, Wu PC, Lam KC, Todd D: Histologic prognostic indicators in hepatocellular carcinoma. Cancer 1979;44:1677-1683.

13 Shah S, Gupta S, Shet T, Maheshwari A, Wuntkal R, Mohandas KM: Metastatic clear cell variant of hepatocellular carcinoma with an occult hepatic primary. Hepatobiliary Pancreat Dis Int 2005;4:306-307.

14 Murakata LA, Ishak KG, Nzeako UC: Clear cell carcinoma of the liver: a comparative immunohistochemical study with renal clear cell carcinoma. Mod Pathol 2000;13:874-881.

15 Wennerberg AE, Nalesnik MA, Coleman WB: Hepatocyte paraffin 1: a monoclonal antibody that reacts with hepatocytes and can be used for differential diagnosis of hepatic tumors. Am J Pathol 1993;143:1050-1054. 